\title{
RENDIMENTO DE FITOMASSA DE MANJERICÃO CULTIVADO EM DIFERENTES AMBIENTES DE LUZ
}

\author{
Lavine Silva Matos ${ }^{1}$; Gilvanda Leão dos Anjos ${ }^{2}$; Diego dos Santos Souza ${ }^{3}$; \\ Nalbert Silva dos Santos ${ }^{3}$; Anacleto Ranulfo dos Santos ${ }^{4}$.
}

1. Mestre em Solos e Qualidade de Ecossistemas da Universidade Federal do Recôncavo da Bahia/UFRB (lavinematos@yahoo.com.br). Cruz das Almas - Brasil. 2. Mestranda em Solos e Qualidade de Ecossistemas da UFRB.

3.Graduandos em Engenharia Agronômica UFRB.

4. Professor Doutor da UFRB.

Recebido em: 08/04/2017 - Aprovado em: 10/06/2017 - Publicado em: 20/06/2017 DOI: 10.18677/EnciBio 2017A92

\begin{abstract}
RESUMO
O manjericão é uma das ervas mais populares e úteis na culinária devido ao seu aroma e sabor, e além disso possui elevados conteúdos de princípios ativos, que apresentam propriedades farmacológicas presentes em inúmeros medicamentos. Avaliou-se diferentes ambientes de luz no rendimento de fitomassa de plantas de Ocimun basilicum L. O trabalho foi realizado entre junho e julho de 2015, na área de experimentos da UFRB, em Cruz das Almas/BA. O delineamento foi 0 inteiramente casualizado com três tratamentos, os quais constituíram-se de diferentes situações de luminosidade: pleno sol, malha fotoconversora vermelha e malha termo-refletora aluminizada, com dez repetições. Foram avaliadas as seguintes características de fitomassa: a altura da planta, diâmetro do caule, comprimento da raiz, número de folhas, massa da matéria seca das folhas, hastes, parte aérea e raiz, e os índices de clorofila. Houve efeito significativo $(p<0,05)$ através do teste $F$ da ANOVA para o número de folhas, massa da matéria seca das folhas, da parte aérea, das raízes e massa da matéria seca total.
\end{abstract}

PALAVRAS-CHAVE: malhas coloridas, nutrição mineral de plantas, Ocimum basilicum $L$.

\section{PHYTOMASS BASIL GROWN IN DIFFERENT LIGHT ENVIRONMENTS}

\begin{abstract}
Basil is one of the most popular and useful in cooking because of its aroma and flavor, and in addition, it has high contents of health services, which cover pharmaceutical products in numerous medicines. The work was carried out in June 2015, in the area of experiments of UFRB, in Cruz das Almas / BA. The design was completely randomized with three treatments, which consisted of different light conditions: full sun, red photoconverter mesh and aluminized thermo-reflective mesh with ten replications. The following phytomass characteristics were evaluated: plant height, stem diameter, leaf length, number of leaves, leaf dry matter weight, stems, shoot and root, and chlorophyll index. There was a significant effect $(p<0.05)$ through the ANOVA $F$ test for leaf number, leaf dry mass, shoot, root and total dry mass
\end{abstract}

KEYWORDS: colored nets, mineral nutrition of plants, Ocimum basilicum L. 


\section{INTRODUÇÃO}

Ocimum basilicum L. se destaca entre as 150 espécies do gênero Ocimum, por causa da sua importância comercial. Planta anual que cresce em várias regiões do mundo e é da família Lamiaceae (SOUZA et al., 2011). Tem sua origem no sudeste asiático e na África Central, trata-se de planta medicinal e aromática conhecida como basílico, alfavaca, alfavaca-cheirosa ou manjericão comum. A espécie possui caule ereto e ramificado, folhas lisas ou onduladas com coloração variando entre tons de verde ou roxo. As flores são pequenas e dispostas e podem adquirir tons de branco, lilás ou vermelhos (FAVORITO et al., 2011).

O manjericão tem uso comercial como aromatizante ou condimento feito com as folhas verdes e aromáticas, que podem ser usadas frescas ou secas. Mas a planta também é utilizada na saúde para curar problemas respiratórios, infecções bacterianas e parasitas intestinais, e na melhoria da digestão dos alimentos. No Brasil a planta e cultivada por pequenos produtores, comercializando as folhas verdes e aromáticas (VIEIRA et al., 2012).

O ambiente e o tipo de cultivo no qual as plantas se desenvolvem, tem influência no seu crescimento e no rendimento de fitomassa. Fatores como intensidade da luz, o fotoperíodo, a temperatura e a nutrição mineral podem influenciar na síntese dos princípios ativos de forma direta ou indireta, por meio do aumento de fitomassa das plantas de espécies que produzem óleos essenciais (SOUZA et al., 2013).

Dentre os fatores que controlam a morfologia e a fisiologia dos vegetais, a luz e o principal, pois afeta de forma complexa pela irradiância todas as etapas do crescimento (SOUZA et al., 2011). Segundo CORRÊA et al. (2012) alterações na qualidade espectral da luz incidente nas plantas têm relação com a sensibilidade que o desenvolvimento das plantas possui há variações ambientais, sendo a intensidade e composição da luz incidente influente na taxa de crescimento celular.

Devido a capacidade que a luz tem em influenciar no desempenho dos vegetais, surgiu no mercado novo conceito de cultivo, as malhas fotoconversoras, as mesmas alteraram a quantidade e qualidade espectral da radiação solar difundida, gerando variações óticas da luz (CHAGAS et al., 2013). Tais malhas, para chegarem ao mesmo efeito de sombreamento (50\%), são unidas mais densamente. A malha vermelha reduz as ondas azuis, verdes e amarelas e aumenta a transmitância em comprimentos de onda acima de 590nm (vermelho) e um pico menor em torno de 400nm (violeta) (SOUZA et al., 2011). Já a malha termorrefletora, tem sido recentemente adotada no Brasil. Elas permitem manobrar a diferença de temperatura entre o dia e a noite, gerando a formação de diferentes microclimas e protege as plantas de excessiva radiação solar (COSTA et al., 2012).

Diversos estudos com plantas medicinais têm apontado a influência das malhas no seu crescimento. Diante do exposto objetivou-se com esse trabalho avaliar a efetividade da ação dos ambientes de luminosidade no rendimento de fitomassa do manjericão.

\section{MATERIAL E MÉTODOS}

O estudo foi realizado em ambiente protegido, entre agosto e setembro de 2015, no Centro de Ciências Agrárias, Ambientais e Biológicas, situado no campus sede da Universidade Federal do Recôncavo da Bahia, situada em Cruz das Almas/BA. As sementes foram germinadas em bandejas de plásticas com 60 células contendo areia lavada como substrato, após emergência, as plântulas receberam diariamente solução nutritiva de HOAGLAND \& ARNON (1950) com 50\% 
da força iônica, por sete dias. Em seguida, o manjericão foi removido da sementeira para vasos contendo $2 \mathrm{dm}^{3}$ de areia lavada e passaram a receber diariamente solução nutritiva de HOAGLAND \& ARNON com 100\% da força iônica (Tabela 1).

TABELA 1 Volumes $(\mathrm{mL})$ utilizados das soluções estoque para formar $1 \mathrm{~L}$ de solução nutritiva completa de HOAGLAND \& ARNON.

\begin{tabular}{cc}
\hline Solução estoque (1M) & $\begin{array}{c}\text { Solução nutritiva completa de } \\
\text { Hoagland e Arnon }\end{array}$ \\
\hline $\mathrm{KH}_{2} \mathrm{PO}_{4}$ & 1 \\
$\mathrm{KNO}_{3}$ & 5 \\
$\mathrm{Ca}\left(\mathrm{NO}_{3}\right)_{2}$ & 5 \\
$\mathrm{MgSO}_{4}$ & 2 \\
Ferro-EDTA & 1 \\
Micronutrientes $^{* *}$ & 1
\end{tabular}

*Solução de Ferro-EDTA: Serão dissolvidos $26,1 \mathrm{~g}$ de EDTA dissódico em $286 \mathrm{~mL}$ de $\mathrm{NaOH} 1 \mathrm{~N}+24,9 \mathrm{~g}$ de $\mathrm{FeSO}_{4} \cdot 7 \mathrm{H}_{2} \mathrm{O}$ e aerado por uma noite. **Solução de micronutrientes (g/l): $\mathrm{H}_{3} \mathrm{BO}_{3}=2,86 ; \mathrm{MnCl}_{2} \cdot 4 \mathrm{H}_{2} \mathrm{O}=1,81 ; \mathrm{ZnCl}_{2}$ $=0,10 ; \mathrm{CuCl}_{2}=0,04 ; \mathrm{H}_{2} \mathrm{MoO}_{4} \cdot \mathrm{H}_{2} \mathrm{O}=0,02$.

O delineamento foi o inteiramente casualizado (DIC) e as plantas cultivadas em três ambientes: pleno sol, malha fotoconversora vermelha e malha termorefletora aluminizada; sendo 10 repetições. Dessa forma, o experimento possuiu 30 unidades experimentais, contendo uma planta/vaso.

No final do trabalho foram avaliadas: a altura, o diâmetro do caule, comprimento da raiz, número de folhas, massa da matéria seca das folhas, hastes, parte aérea e raiz, e os índices de clorofila. O comprimento da raiz e a altura do manjericão foram determinados utilizando-se uma régua graduada, o diâmetro das hastes foi aferido com um paquímetro digital, $0 \mathrm{n}^{0}$ de folhas foi determinado por contagem direta.

O material vegetal foi seco em estufa a $65^{\circ} \mathrm{C}$ por $72 \mathrm{~h}$, após esse período obteve-se os valores de massa de matéria seca (folhas, hastes, parte aérea e raiz) utilizandose balança de precisão (três casas decimais). A área foliar foi determinada pelo método dos discos foliares e de formula matemática, em seguida, obteve-se a área foliar específica e, por fim, a razão de área foliar, conforme metodologia indicada por PEIXOTO et al. (2011). Para determinar os índices de clorofila, utilizou-se a média das leituras de três folhas do terço médio de cada planta (Clorofilômetro Eletrônico clorofiLOG CFL 1030 da Falker), entre 08 as 10 horas da manhã. Realizou-se análise de variância pelo teste $\mathrm{F}$ nos dados coletados e para os casos em que houve significância, efetuou-se o teste de Tukey $(p<0,05)$.

\section{RESULTADOS E DISCUSSÃO}

O número de folhas e a massa da matéria seca das frações da planta (Tabela 1) apresentaram efeito significativo devido aos diferentes ambientes de luz $(p<0,05)$ pelo teste $\mathrm{F}$ da análise de variância. 
TABELA 1. Resumo ANAVA para: número de folhas (NF), massa da matéria seca das folhas, parte aérea, raízes e total (MSF, MSPA, MSR, MST).

\begin{tabular}{|c|c|c|c|c|c|}
\hline $\begin{array}{l}\text { FONTES DE } \\
\text { VARIAÇÃOO }\end{array}$ & NF & MSF & MSPA & MSR & MST \\
\hline & & $-Q U$ & DOS N & & \\
\hline $\mathrm{AL}$ & $5510,70^{*}$ & $2,36^{*}$ & $3,99^{\star}$ & $75,69^{*}$ & $75,45^{\star}$ \\
\hline Resíduo & 786,52 & $0,57^{*}$ & 1,11 & 4,79 & 5,81 \\
\hline CV (\%) & 25,15 & 12,58 & 9,88 & 35,57 & 14,32 \\
\hline Média geral & 111,50 & 6,01 & 10,67 & 6,15 & 16,83 \\
\hline
\end{tabular}

$\mathrm{AL}$ - ambiente de luz; ${ }^{\text {ns }}$ - não significativo; ${ }^{*} \mathrm{e}^{* *}$ - significativo ao nível de $5 \%$ e de $1 \%$ pelo teste $\mathrm{F}$.

A altura da planta (AP), o diâmetro do caule (DC), comprimento da raiz (CR), massa de matéria seca do caule (MSC), área foliar (AF), área foliar específica (AFE), razão de área foliar (RAF) e índices de clorofila (IC) não apresentaram diferenças estatísticas. As plantas sob malhas não apresentaram diferença estatística, mas houve diferença entre estas e aquelas sob pleno sol (Figura 1). Percentualmente, a diferença encontrada entre as plantas sob pleno sol foi de $46,8 \%$ e $35,2 \%$ em relação as sob malha vermelha e a aluminizada, respectivamente. Isto sugere, que o ambiente de pleno sol proporcionou aumento no metabolismo da planta que resultou em maior emissão de folhas.

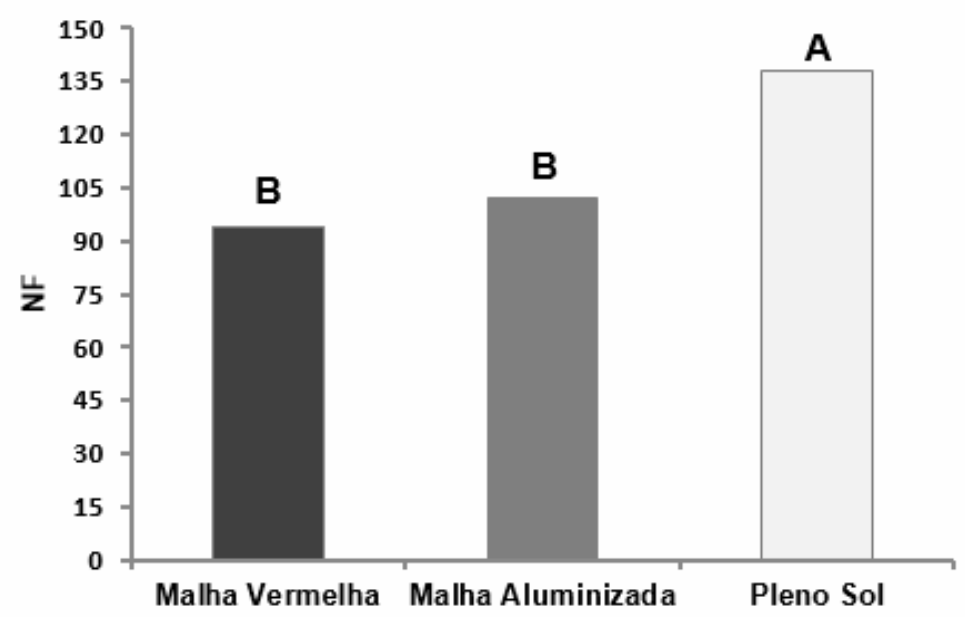

FIGURA 1: Número de folhas (NF) de manjericão cultivado em diferentes ambientes de luminosidade.

Os resultados apresentados foram semelhantes aos encontrado por GUERRA et al. (2015), trabalhando com a caracterização agronômica de O. gratissimum L. e Ocimum sp. crescidos em ambiente protegido e ambiente externo, em que observaram que as plantas com maior NF foram aquelas sob pleno sol. MATOS et al. (2016), avaliando manjericão produzido com diferentes doses de potássio (K) e ambientes de luz, constataram que na dose zero de $\mathrm{K}$ (testemunha), as plantas sob pleno sol e malha vermelha não diferiram significativamente, a diferença estatística significativa ocorreu somente entre as plantas sob malhas. 
A massa de matéria seca das folhas (Figura 2) do manjericão sob malha vermelha diferiu de forma significativa apenas da malha aluminizada. Percentualmente, esta diferença foi de $15,8 \%$, tendo o ambiente de malha vermelha proporcionado a maior massa de matéria seca. Ambas malhas não apresentaram diferença significativa quando comparadas as plantas em pleno sol.

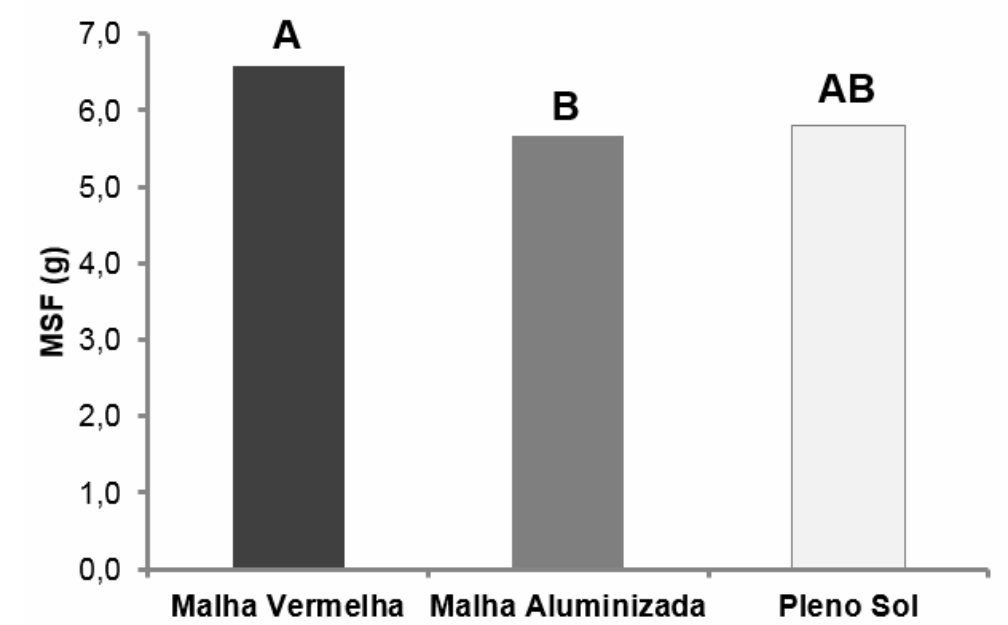

FIGURA 2: Massa de matéria seca das folhas (MSF) de manjericão cultivado em diferentes ambientes de luminosidade.

PAULUS et al. (2016), verificaram que a massa de matéria seca de plantas de manjericão sob pleno sol foi maior e estatisticamente diferente das plantas dos demais ambientes de luz, resultado diferente do encontrado nesse trabalho. Já CHAGAS et al. (2013) em trabalho com hortelã-japonesa, concluíram que isso se deve ao fato desta espécie ter maior sensibilidade à intensidade da luz no que tange ao rendimento de fitomassa das folhas, pois o sombreamento fornecido pelas malhas $(50 \%)$ foi prejudicial às plantas, qualquer que fosse a cor, não beneficiando quando comparadas às plantas sob pleno sol.

Diferentemente, PINHEIRO et al. (2012), avaliando plantas de rúcula sob malhas, verificaram a ausência de diferença estatística para esse parâmetro em função da qualidade da luz, o que se explica pela similaridade das temperaturas diárias (médias) nas malhas utilizadas durante o experimento. Assim como ocorreu com a MSF, a MSPA também só diferiu de forma significativa entre plantas sob malhas, tendo a vermelha proporcionado rendimento de MSPA $12 \%$ superior ao daquelas sob malha aluminizada (Figura 3). 


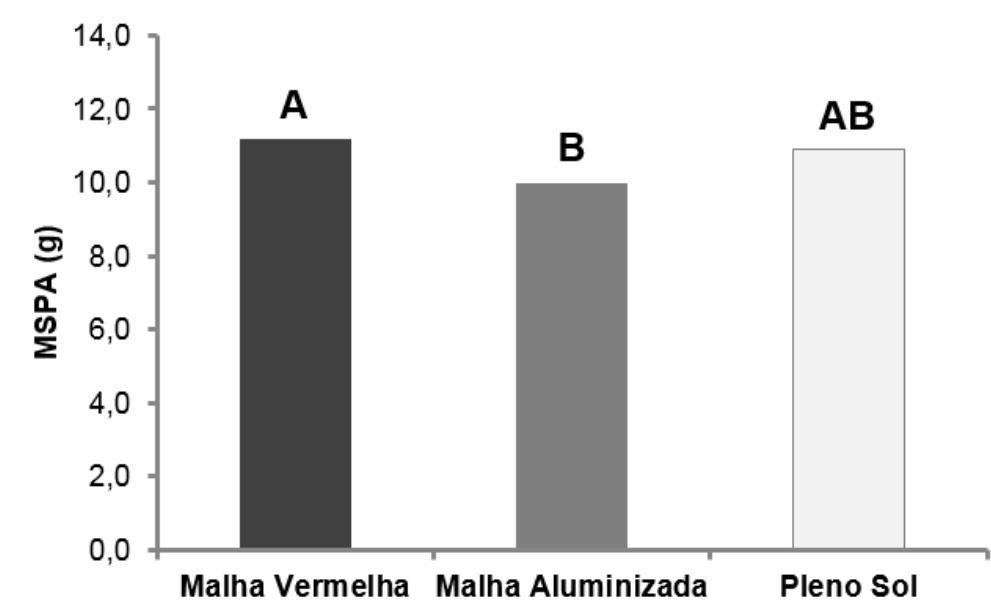

FIGURA 3: Massa de matéria seca da parte aérea (MSPA) de manjericão cultivado em diferentes ambientes de luminosidade.

RIBEIRO (2015) ao avaliar cultivo de Patchouli sob malhas, concluíram que as plantas obtiveram maiores valores de MSPA quando sob malha vermelha. Em estudo com Mentha piperita L., SOUZA et al. (2013) também encontraram resultados semelhantes. Tais resultados possivelmente estão relacionados à maior aporte de fótons na região entre vermelho e vermelho-distante, o que acaba favorecendo a fotossíntese, sugerindo o estimulo ao crescimento e vigor vegetativo das plantas, pela malha vermelha.

PAULUS et al., (2016) em trabalho com manjericão sob malhas, constataram que a MSPA apresentou efeito significativo em razão do ambiente de luminosidade, tendo o manjericão cultivado no ambiente de pleno sol apresentado os melhores desempenhos. Os valores de massa de matéria seca das raízes (Figura 4) foram maiores no manjericão sob pleno sol e diferiram significativamente da MSR daquelas sob malhas, independentemente da cor. Percentualmente, a MSR do manjericão sob pleno sol foi $54,3 \%$ e $154 \%$ superior à MSR das plantas nos ambientes sob malha aluminizada e vermelha, respectivamente.

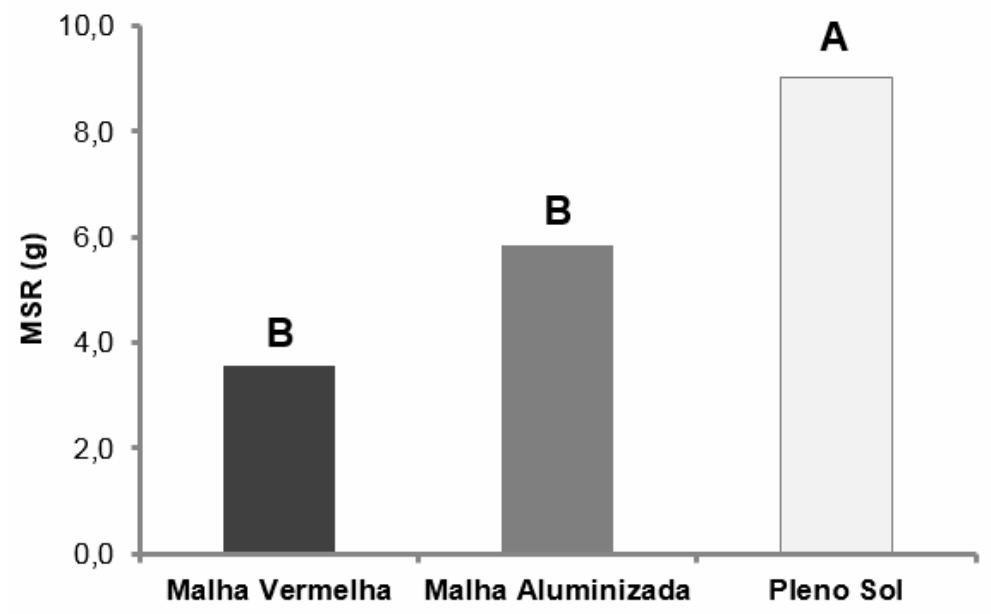

FIGURA 4: Massa de matéria seca das raízes (MSR) de manjericão cultivado em diferentes ambientes de luminosidade. 
Em estudo com Artemisia vulgaris L. sob malhas coloridas, OLIVEIRA et al. (2009), concluíram que aquelas sob $100 \%$ de radiação (pleno sol) apresentaram maiores valores de MSR. Contrariamente, BRANT et al. (2009) apresentaram resultados contrários ao deste estudo, pois a melissa apresentou fitomassa de raiz maior sob ambiente com malha vermelha, assim, diferindo estatisticamente dos outros ambientes de luminosidade avaliados. As plantas sob pleno sol obtiveram rendimento de MST $35,4 \%$ e $26 \%$ maior do que aquelas cultivadas nos ambientes com malha vermelha e aluminizada, respectivamente (Figura 5).

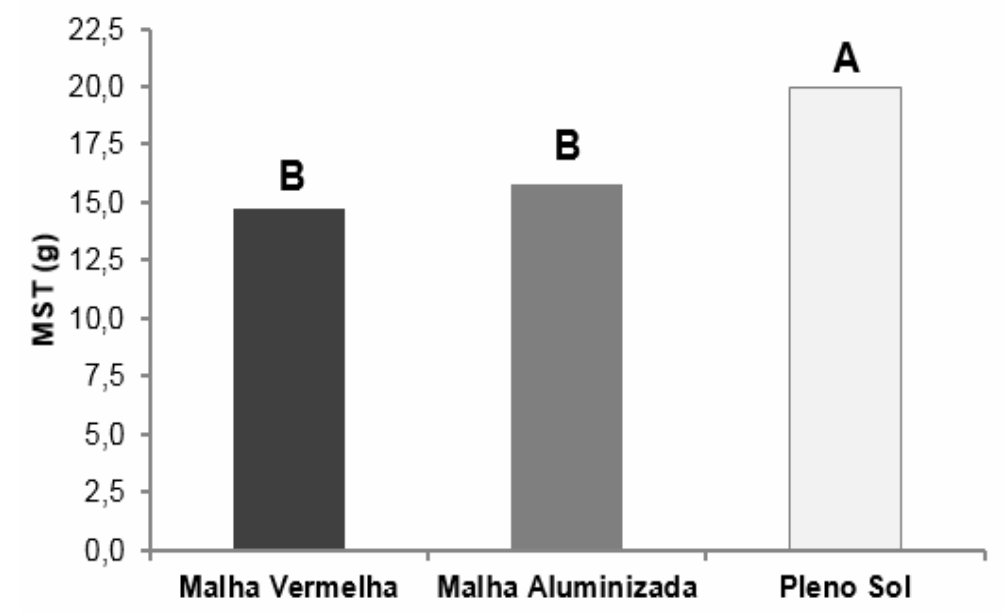

FIGURA 5: Massa de matéria seca total (MST) do manjericão cultivado em diferentes ambientes de luminosidade.

Estes resultados corroboram os de CHAGAS et al. (2014), que avaliaram plantas de hortelã-japonesa cujo maior rendimento de fitomassa total foi sob pleno sol, diferindo significativamente daquelas crescidas nos outros ambientes de luminosidade avaliados. Semelhantemente, em estudo com Artemisia vulgaris L. realizado por OLIVEIRA et al. (2009). Assim, pode-se considerar que tais espécies apresentam maior rendimento de MST sob pleno sol, não sendo fortemente influenciadas pelo cultivo sombreado com ou sem alteração da qualidade espectral da luz.

\section{CONCLUSÕES}

O cultivo de manjericão sob pleno sol proporcionou maior rendimento de folhas, de massa de matéria seca da raiz e total.

O maior rendimento de massa de matéria seca das folhas e da parte aérea do manjericão foi obtido quando cultivado com malha vermelha.

Os diferentes ambientes de luz não influenciaram a altura da planta, o diâmetro do caule, comprimento da raiz, massa de matéria seca do caule, área foliar, área foliar específica, a razão de área foliar e o índices de clorofila no manjericão. 


\section{AGRADECIMENTOS}

A UFRB, pela oportunidade de realizar este experimento e a FAPESB pelo apoio financeiro.

\section{REFERÊNCIAS}

BRANT, R. S.; PINTO, J. E. B. P.; ROSA, L. F.; ALBUQUERQUE, C. J. B.; FERRI, P. H.; CORRÊA, R. M. Crescimento, teor e composição do óleo essencial de melissa cultivada sob malhas fotoconversoras. Ciência Rural, v.39, n.5, p.1401-1407, 2009.

CHAGAS, J. H.; PINTO, J. E. B. P.; BERTOLUCCI, S. K. V.; COSTA, A. G.; JESUS, H. C. R.; ALVES, P. B. Produção, teor e composição química do óleo essencial de hortelã-japonesa cultivada sob malhas fotoconversoras. Horticultura Brasileira. v. 31, n. 2, 297-303, 2013.

CORRÊA, R. M.; PINTO, J. E. B.; REIS, É. S.; MOREIRA, C. Crescimento de plantas, teor e qualidade de óleo essencial de folhas de orégano sob malhas coloridas. Global Science and Technology, v.05, n.01, p.11 - 22, 2012.

COSTA, A. G.; CHAGAS, J. H.; PINTO, J. E. B. P.; BERTOLUCCI, S. K. V. Crescimento vegetativo e produção de óleo essencial de hortelã-pimenta cultivada sob malhas. Pesquisa Agropecuária Brasileira, v.47, n.4: p.534-540, 2012.

GUERRA, M. E. de C.; MEDEIROS FILHO, S.; COSTA, I. R.; FREITAS, J. B. S.; OLIVEIRA, A. B. Caracterização agronômica de ocimum gratissimum L. (alfavacacravo) e Ocimum sp (alfavaca-roxa) cultivadas em casa de vegetação e ambiente externo. Cultura Agronômica, v. 23, n. 2, p.123-134, 2015.

FAVORITO, P. A.; ECHER, M. M.; OFFEMANN, L. C.; SCHLINDWEIN, M. D.; COLOMBARE, L. F.; SCHINEIDER, R. P.; HACHMANN, T. L. Características produtivas do manjericão (Ocimum basilicum L.) em função do espaçamento entre plantas e entre linhas. Revista Brasileira de Plantas Medicinais, v.13, especial, p. 582-586, 2011. Disponível em: <http://dx.doi.org/10.1590/S151605722011000500013 >. Doi: 10.1590/S1516-05722011000500013.

HOAGLAND, D. R.; ARNON, D. I. The water culture method for growing plants without soils. Berkeley: California Agricultural Experimental Station, 347p. 1950.

MATOS, L. S.; SOUZA, D. S.; SANTOS, N S.; ANJOS, G. L.; SANTOS, A. R. Crescimento inicial e índices de clorofila de manjericão cv. Maria bonita cultivado sob diferentes condições de Luminosidade e concentrações de potássio. Enciclopédia Biosfera, v.13 n.23, p.388-397, 2016. Disponível em: $<10.18677 /$ Enciclopedia_Biosfera_2016_034>.Doi:10.18677/Enciclopedia_Biosfera_ 2016_034.

OLIVEIRA, M. I.; CASTRO, E. M.; COSTA, L. C. B.; OLIVEIRA, C. Características biométricas, anatômicas e fisiológicas de Artemisia vulgaris L. cultivada sob telas coloridas. Revista Brasileira de Plantas Medicinais, v.11, n.1, p.56-62, 2009. 
Disponível em: <http://dx.doi.org/10.1590/S1516-05722009000100010>. Doi: 10.1590/S1516-05722009000100010.

PAULUS, D.; VALMORBIDA, R.; FERREIRA, S. B.; ZORZZI, I. C.; NAVA, G. A. Biomassa e composição do óleo essencial de manjericão cultivado sob malhas fotoconversoras e colhido em diferentes épocas. Horticultura Brasileira. v.34, n.1, p.046-053, 2016. Disponível em: <http://dx.doi.org/10.1590/S0102053620160000100007>. Doi: 10.1590/S0102-053620160000100007.

PEIXOTO, C. P.; CRUZ, T. V.; PEIXOTO, M. F. S. Análise quantitativa do crescimento de plantas: Conceitos e Prática. Enciclopédia Biosfera, v.7, n.13, p.5176, 2011.

PINHEIRO, R. R. SCHMIDT, D.; CARON, B. O.; BOSCAINI, R. Efeito de diferentes malhas de sombreamento na emergência e produção de mudas de rúcula. Enciclopédia Biosfera, Goiânia, v.8, n.15, p.757-766, 2012.

RIBEIRO, A. S. Cultivo sob malhas no crescimento, desenvolvimento e composição química do óleo essencial de Patchouli. Dissertação (Mestrado) Curso de Pós-Graduação em Plantas Medicinais, Aromáticas e Condimentares, Universidade Federal de Lavras, Lavras, 98 f., 2015.

SOUZA, N. H.; CARNEVALI, T. O.; RAMOS, D. D.; SCALON, S. P. Q.; MARCHETTI, M. E.; VIEIRA, M. C. Produção de mudas de manjericão (Ocimum basilicum L.) em diferentes substratos e luminosidades. Revista Brasileira de Plantas Medicinais, v.13, n.3, p. 276-281, 2011. Disponível em: <http://dx.doi.org/10.1590/S151605722011000300005>. Doi: 10.1590/S1516-05722011000300005.

SOUZA, G. S.; SILVA, J. S.; SANTOS, A. R.; GOMES, D. G.; OLIVEIRA, U. C. Crescimento e produção de pigmentos fotossintéticos em alfavaca cultivada sob malhas coloridas e adubação fosfatada. Enciclopédia Biosfera, v.7, n.13, p.296306, 2011.

SOUZA, G. S.; OLIVEIRA, U. C.; SILVA, J. S.; LIMA, J. C. Crescimento, produção de biomassa e aspectos fisiológicos de plantas de Mentha piperita L. cultivadas sob diferentes doses de fósforo e malhas coloridas. Global ScienceTechnology, v.06, n.03, p.35-44, 2013.

VIEIRA, M. C.; CARLESSO, A.; HEREDIA ZÁRATE, N. A.; GONÇALVES, W. L. F.; TABALDI, L. A.; MELGAREJO, E. Consórcio de manjericão (Ocimum basilicum L.) e alface sob dois arranjos de plantas. Revista Brasileira de Plantas Medicinais, v. 14, n.14, p.169-174, 2012. Disponível em: <http://dx.doi.org/10.1590/S151605722012000500008 >. Doi: 10.1590/S1516-05722012000500008. 